\title{
ANALISIS PENGARUH KOMUNIKASI, DISIPLIN KERJA, DAN MOTIVASI TERHADAP KINERJA PEGAWAI BADAN PUSAT STATISTIK KABUPATEN PROBOLINGGO
}

\section{Totok Harianto*}

Abstract: In order to support bureaucratic reform within the central statistical agency of probolinggo district, it is demanded human resources that have good performance. From some of the phenomenon observed can be seen that communication, work discipline and motivation as a variable that has an influence on the performance of the Central Statistics Agency employees Probolinggo.

The purpose of this research are: (1) Analyze and describe the influence of simultaneous (variant) of communication, work discipline, and motivation toward employee performance of Central Bureau of Statistics of Probolinggo Regency. (2) Analyze and describe the influence individually (partial) of communication, work discipline, and motivation to the performance of employees of Central Bureau of Statistics of Probolinggo Regency. (3) Analyze and describe which variable is the biggest influence between communication, work discipline, and motivation to employee performance of Central Bureau of Statistics of Probolinggo Regency.

The sample in this study is a population of 35 people from all employees of the Central Bureau of Statistics of Probolinggo Regency. Analysis technique used duntuk know variable $(\mathrm{X})$ to variable not free (Y) by using doubled linear regression.

The results of this study indicate that: (1) communication, work discipline, and motivation have influence in the significant increase of work equal to $79,9 \%$. While the rest of $20.1 \%$ is influenced by other variables that are not examined. (2) communication, work discipline, and motivation together affect performance. This can be indicated by the F test value of 0.000 smaller 0.05 . (3) the variables of communication, work discipline, and motivation affect each performance. This is indicated by the significance of the t test of each variable less than 0.05 . (4) work discipline variable has a dominant influence on performance. This is indicated by the beta value of 0.468 is greater among other variables

Keywords: statistical agency, probolinggo district, good performance.

\section{A. Pendahuluan}

* Kepala Biro Akademik Institut Ilmu Keislaman Zainul Hasan Kraksaan Probolinggo 
Badan Pusat Statistik (BPS) merupakan Lembaga Pemerintah NonDepartemen yang memiliki peran untuk menyediakan kebutuhan data bagi pemerintah dan masyarakat. Data dan informasi statistik yang dihasilkan badan pusat statistik digunakan sebagai bahan rujukan untuk menyusun perencanaan, melakukan evaluasi, membuat keputusan dan memformulasikan kebijakan.

Tuntutan masyarakat terhadap ketersediaan data dan informasi statistik yang beragam semakin hari semakin meningkat. Pengguna data menginginkan data bias tersedia lebih cepat, lebih murah serta mudah dieroleh, dan lebih berkualitas. Upaya pengembangan yang dilakukan Badan Pusat Statistik sampai saat ini telah menghasilkan beragam data dan indicator sosial-ekonomi. Meskipun demikian Badan Pusat Statistik tidak jarang mendapat kritik karena dinilai tidak mencerminkan realitas dilapangan. Pro dan Kontra mengenai data yang dihasilkan Badan Pusat Statistik mengindikasikan bahwa kualitas data Badan Pusat Statistik masih perlu dibenahi dan ditingkatkan.

Berbagai upaya perbaikan telah dilakukan Badan Pusat Statistik dalam rangka mendukung peningkatan kinerja aparatur guna menjawab keinginan pemerintah dan masyarakat terhadap data yang berkualitas. Badan Pusat Statistik harus mampu menyajikan data dan informasi statistik yang dapat dipercaya, relevan dan tepat waktu melalui proses kerja yang sistematis tanpa distorsi. Untuk memenuhi tuntuan masyarakat yang tinggi, diperlukan perubahan budaya kerja dan pola berfikir dari seluruh jajaran Badan Pusat Statistik baik dari para pimpinan maupun staf yang paling bawah. Oleh sebab itu Badan Pusat Statistik mempunyai tekad yang kuat untuk melakukan pembaharuan dan perubahan serta perubahan yang mendasar terhadap system penyelenggaraan kegiatan statistik dengan melakukan reformasi birokrasi (Renstra BPS 2010-2014).

Tujuan dari Badan Pusat Statistik Kabupaten Probolinggo yang mengacu pada visi-misi adalah sebagai berikut :

1. Meningkatkan ketersediaan data dan informasi statistik yang berkualitas serta pelayanan prima dalam rangka mewujudkan SSN yang handal, efektif dan efisien.

2. Peningkatan koordinasi dengan instansi terkait, integrase dan singkronisasi serta standarisasi seluruh penyelenggaraan kegiatan statistik sectoral dan statistik khusu.

3. Melakukan reformasibirokrasi dengan menerapkan peningkatan kualitas data, pembinaan dan peningkatan kualitas sumber daya manusia, penguatan Tekhnologi Informasi Dan Komunikasi (TIK) serta sarana kerja serta penguatan kelembagaan dan hubungan dengan sumber penggunaan data.

Untuk mewujudkan tujuan tersebut, perubahan dan pembaharuan system kegiatan statistik dibutuhkan pemimpin yang berkarakter untuk membawa Badan Pusat Statistik kearah yang lebih baik. 
Dari beberapa kreteria bagaimana seorang pemimpin yang efektif, teori kepemimpinan seperti yang disampaikan oleh Judge dan Bono (2000) dalam Bambang Sudarmanto (2011) tentang efektifitas pemimpin sesuai dengan keseharian yang ada dilapangan Badan Pusat Statistik Kabupaten Probolinggo yaitu komunikasi, disiplin dan motivasi. ${ }^{1}$

Komunikasi merupakan hal yang sangat vital dan efektif untuk menumbuhkan partisipasi serta meningkatkan hubungan secara dinamis antara orang-orang serta menterjemahkan tujuan kedalam unit-unit kegiatan yang konkrit dalam suatu pelaksanaan program guna mencapai tujuan organisasi. Komunikasi yang efektif menurut Nimran adalah adanya kemampuan dan kemauan mendengar secara aktif, dan adanya kemampuan dan kemauan untuk memberikan timbal balik secara aktif. Sebagai pemimpin diharapkan akan mendorong pegawainya untuk dapat berkomunikasi secara aktif agar dapat menggerakkan kinerja pegawai kearah yang lebih baik tentunya.

\section{B. Pembahasan}

Hasil analisis regresi selanjutnya diringkas dalam table 4.9 sebagai berikut

Tabel 4.9

Hasil Analisis Regresi

Model Summary

\begin{tabular}{|c|r|r|r|r|r|}
\hline Model & R & R Square & $\begin{array}{r}\text { Adjusted } \\
\text { R Square }\end{array}$ & $\begin{array}{r}\text { Std. Error } \\
\text { of the } \\
\text { Estimate }\end{array}$ & $\begin{array}{c}\text { Durbin- } \\
\text { Waston }\end{array}$ \\
\hline 1 &, $899^{\mathrm{a}}$ &, 799 &, 786 & .20069 & 1.238 \\
\hline
\end{tabular}

a. Predictors: (Constant), X3RATA, X2RATA, X1RATA

b. Dependent Variable: YRATA

\begin{tabular}{|c|c|c|c|c|c|c|}
\hline \multicolumn{7}{|c|}{ ANOVA $^{b}$} \\
\hline \multicolumn{2}{|c|}{ Model } & Sum of & df & Mean Square & $\mathrm{F}$ & Sig \\
\hline 1 & $\begin{array}{l}\text { Regression } \\
\text { Residual } \\
\text { Total }\end{array}$ &, $899^{\mathrm{a}}$ & ,799 & ,786 & .20069 & 1.238 \\
\hline
\end{tabular}

a. Predictors: (Constant), X3RATA, X2RATA, X1RATA

${ }^{1}$ Judge, T.A., dan J.E. Bono, (2007). Five-factor Model of Personality and Five-Factor Model of Personality and transactional Leadership. Journal of Aplied Psychology, 85 (5) : 751765 
b. Dependent Variable: YRATA 
Coefficients

\begin{tabular}{|c|c|c|c|c|c|c|c|c|}
\hline \multicolumn{2}{|c|}{ Model } & \multicolumn{2}{|c|}{$\begin{array}{c}\text { Unstandardized } \\
\text { Coeficients }\end{array}$} & \multirow{2}{*}{$\begin{array}{c}\text { Standardize } \\
\mathrm{d} \\
\text { Coeficients } \\
\text { Beta }\end{array}$} & \multirow[b]{2}{*}{$\mathrm{t}$} & \multirow[b]{2}{*}{ Sig. } & \multicolumn{2}{|c|}{$\begin{array}{c}\text { Collinearity } \\
\text { Statistics }\end{array}$} \\
\hline & & B & Std. Error & & & & $\begin{array}{c}\text { Toleranc } \\
\mathrm{e}\end{array}$ & VIF \\
\hline 1 & (Constant) & 1.586 & .420 & & 3.775 & .001 & & \\
\hline & X1RATA & , 166 & .133 & ,206 & 1,467 &, 025 & .619 & 1.61 \\
\hline & X2RATA & .486 & .084 & .677 & 5.582 & .000 & .826 & 1.21 \\
\hline & X3RATA & .298 & .086 & .450 & 3.446 & .002 & .713 & 1.40 \\
\hline
\end{tabular}

a. Dependent Variable : YRATA

Sumber : Data Primer diolah, Tahun 2013

Memperhatikan table 4.9 dapat dijelaskan sebagai berikut :

1. R Square $=0,799$ (Lampiran 5, table Model Summary). Dikatakan bahwa komunikasi, disiplin kerja dan motivasi dapat menjelaskan perubahan kinerja pegawai atau dengan kata lain memiliki pengaruh dalam peningkatan kinerja yang cukup signifikan sebesar 79,9\%. Sementara sisanya sebesar $20,1 \%$ dipengaruhi oleh variable lain yang tidak diteliti.

2. Nilai Beta atas variable komunikasi positif 0,166. Dikatakan bahwa komunikasi berpengaruh positif terhadap produktifitas kerja. Jika indicator-indikator komunikasi ditingkatkan keberadaannya, maka kinerja juga akan meningkat sebesar 0,166 satuan. Dengan anggapan variable lain kosntan.

3. Nilai Beta atas variable disiplin kerja 0,486. Dikatakan bahwa disiplin kerja berpengaruh positif terhadap kinerja. Jika indicator-indikator disiplin kerja ditingkatkan keberadaannya, maka kinerja juga meningkat sebesar 0,468 satuan. Dengan anggapan variable lain kosntan.

4. Nilai Beta atas variable motivasi menunjukkan positif 0,298. Dikatakan bahwa motivasi ditingkatkan keberadaannya, maka kinerja juga meningkat sebesar 0,298 satuan. Dengan anggapan variable lain kosntan.

\section{Uji Hipotesis}

1. Hipotesis pertama

Memperhatikan Tabel 4.9 terlihat bahwa nilai signifikansi uji $\mathrm{F}$ sebesar 0,000 lebih kecil alpha 0,05. Dari hasil perhitungan, dapat dijelaskan bahwa hipotesis pertama yang menyatakan bahwa komunikasi, disiplin kerja, dan motivasi secara bersama-sama berpengaruh terhadap kinerja diterima atau didukung oleh data empiris.

2. Hipotesis kedua

Memperhatikan Tabel 4.9 terlihat bahwa nilai signifikansi uji t setiap variable lebih kecil alpha 0,05. Dari hasil perhitungan dapat dijelaskan 
bahwa komunikasi, disiplin kerja, dan motivasi kerja masing-masing berpengaruh terhadap kinerja diterima atau didukung oleh data empiris.

3. Hipotesis ketiga

Memperhatikan Tabel 4.9 terlihat bahwa nilai beta atas variable disiplin kerja lebih besar disbanding variable komunikasi dan variable motivasi. Dari hasil perhitungan dapat dijelaskan bahwa hipotesis ketiga yang menyatakan bahwa variable komunikasi berpengaruh paling besar terhadap kinerja tidak diterima, karena ternyata dari hasil perhitungan yang berpengaruh paling besar terhadap kinerja Pegawai Badan Pusat Statistik Kabupaten Probolinggo adalah variable disiplin kerja yang didukung dengan data empiris.

Kinerja dalam penelitian ini dipengaruhi oleh variabel komunikasi, disiplin kerja, dan motivasi serta variabel disiplin kerja berpengaruh paling besar terhadap kinerja pegawai. Oleh karena itu, pihhak kantor Badan Pusat Stattistik Kabupaten Probolinggo sangat perlu memperhatikan factor-faktor yang bias meningkatkan disiplin kerja pegawainya.

Komunikasi yang dilakukan atasan tidak berpengaruh besar terhadap kinerja, hal ini tidak seperti pada hipotesis dalam penelitian ini. Dari dugaan awal dan fenomena yang ada, Pimpinan BPS Kabupaten Probolinggo merasakan bahwa cara berkomunikasi dirasakan perlu diperbaiki agar bawahan lebih paham atas pengarahan dan instruksi yang disampaikan. Hal ini menunjukkan bahwa pimpinan BPS kabupaten probolinggo ingin mendapatkan masukan dari bawahan atas kepemimpinannya, dan sebelum membuat kebijakan dalam rangka peningkatan kinerja bawahan, pimpinan terlebih dahulu agar melakukan intropeksi diri atas kinerjanya sebagai pimpinan dimata bawahannya.

Namun, hasil uji data didalam penelitian ini telah menunjukkan bahwa komunikasi Pimpinan BPS Kabupaten Probolinggo dimata bawahannya sudah baik, justru pegawai menyetujui dan menyukai situasi yang dapat menegakkan disiplin, hal ini terlihat dari jawaban pernyataan dalam kuesioner, yaitu :

1. Indikasikan bahwa pegawai taat pada peraturan yang berlaku

2. Adanya indikasi bahwa pegawai selalu melaksanakan apa yang diperintahkan oleh atasan.

3. Pegawai selalu dapat menyelesaikan pekerjaan sesuai dengan waktu yang telah ditentukan.

4. Bahwa pegawai selain patuh terhadap atasan, juga memiliki kesanggupan untuk melaksanakan apa yang diperintahkan kepadanya.

Uraian tersebut diatas yang didapat dari data emperis atas hasil pengolahan data didalam penelitian ini, yang menunjukkan bahwa pegawai Badan Pusat Statistik Kabupaten Probolinggo saat menjunjung nilai 
kedisiplinan. Oleh Karen itu perlu diperhatikan untuk memberikan stimulus yang posistif pada indicator-indikator didalam variabel disiplin kerja seperti yang diuraikan dalam penelitian ini demi untuk meningkatkan kinerja pegawai.

Disiplin merupakan faktor utama dalam organisasi, disiplin yang baik mencerminkan tanggung jawab seseorang terhadap tugas-tugas yang diembankan kepadanya. Adapun faktor-faktor yang mempengaruhi disiplin ${ }^{2}$ adalah :

1. Tujuan dan Kemampuan

Tujuan dan kemampuan ikut mempengaruhi tingkat kedisiplinan karyawan.tujuan harus jelas dan diterapkan secara ideal.

2. Teladan Pemimpin.

Teladan pemimpin ini sangat berpengaruh dalam menentukan kedisiplinan karyawan, karena pemimpin dijadikan teladan oleh para bawahannya.

3. Balas Jasa

Balas jasa (gaji dan kesejahteraan) ikut mempengaruhi kepuasan dan kecintaan karyawan terhadap pekerjaannya. Jadi dengan semakin besar balas jasa semakin baik kedisiplinan karyawan begitu pula sebaliknya.

4. Keadilan

Keadilan yang dijadikan dasar kebijaksanaan dalam pemberian balas jasa (pengakuan) atau hukuman, maka akan merangsang kedisiplinan karyawan yang baik.

5. Sanksi Hukuman

Sanksi hukuman berpengaruh dalam memelihara kedisiplinan karyawan, karena dengan sanksi hukuman yang semakin berat karyawan akan semakin takut untuk melanggar peraturan-peraturan yang telah ditetapkan.

6. Ketegasan

Ketegasan pemimpin dalam melakukan tindakan akan mempengaruhi kedisiplinan karyawan. Pimpinan harus berani dan tegas bertindak untuk menghukum karyawan yang indisipliner dengan sanksi dan hukuman yang telah ditetapkan.

7. Hubungan dan Kemanusiaan

Hubungan kemanusiaan yang harmonis diantara semua karyawan ikut menciptakan kedisiplinan yang baik pada organisasi. Jika pemimpin mampu menciptakan suasana yang serasi maka terwujud lingkungan suasana kerja yang nyaman.

${ }^{2}$ Handoko, T.H. (2001) Manajemen Personalia Dan Sumberdaya Manusia. Edisi Kedua. BPFE. Yogyakarta 
Walaupun begitu komunikasi tetap merupakan salah satu elemen manajemen yang penting dalam suatu organisasi karena berfungsi sebagai sarana untuk mengkoordinasikan pekerjaan pada bagian-bagian yang terpisah. Pola komunikasi dalam organisasi yang erat kaitannya dengan fungsi atasan sebagai manajer dan koordinator adalah pola komunikasi atasan kepada bawahan. Komunikasi atasan kepada bawahan adalah pola komunikasi yang mengalir dari individu di tingkat yang lebih tinggi kepada individu yang lebih rendah dalam suatu hirarki organisasi. Komunikasi atasan kepada bawahan seperti dikatakan oleh Muhammad memegang peranan yang sangat penting karena berkaitan dengan peran atasan sebagai pepimpin dalam organisasi. ${ }^{3}$ Melalui pola komunikasi ke bawah, atasan menjelaskan kepada bawahan mengenai pekerjaan yang harus dilakukan serta memberikan informasi yang diperlukan untuk mengabil suatu keputusan, mengarahkan kinerja bawahan, memicu motivasi kerja pegawai, serta mengandilakan perilaku semua karyawan. Komunikasi atasan kepada bawahan yang berjalan baik akan menjadi kekuatan bagi organisasi dalam memaksimalkan konstribusinya bagi kesejahteraan para anggotanya dan masyarakat yang lebih luas. ${ }^{4}$ Komunikasi suatu organisasi dapat mempengaruhi kinerja pegawainya. Komunikasi didalam organisasi memiliki pengaruh penting dalam produktifitas organisasi karena komunikasi organisasi secara tidak langsung dapat mempengaruhi usaha organisasi.

Dalam kegiatan organisasi terdapat pengaruh anatara motivasi terhadap kinerja, kuat lemahnya motivasi seseorang menentukan besar kecilnya kinerja sehingga banyak faktor yang mempengaruhi kinerja karyawan. Karyawan bekerja dengan produktif tergantung pada motivasi, kepuasan kerja, desain pekerjaan, kondisi fisik pekerjaan serta perilaku yang lainnya. Perilaku seseorang pada dasarnya tidak terlepas dari motif-motif yang melatarbelakangi. Motivasi seseorang terbentuk dalam dirinya yang berawal daro kebutuhan serta keinginan dan dorongan untuk bertindak demi tercapainya tujuan. Bila keinginan sudah tercapai biasanya dorongan itu secara otomatis akan melemah dan berkurang, dan selanjutnya diperlukan penguat baru. Pada dasarnya keinginan manusia untuk mencapai kepuasan, sehingga ada dorongan kuat dari dirinya untuk mewujudkannya. Suatu pekerjaan dalam hubungannya dengan pencapaian hasil/prestasi dipengaruhi oleh motivasi yang mendasari manusia untuk melakukan pekerjaan. ${ }^{5}$ Dengan demikian orang yang tinggi motivasinya tetapi memiliki ability yang rendah maka akan

\footnotetext{
${ }^{3}$ Muhammad, A. (2009), Komunikasi Organisasi. Ed.I Cet.10. Bumi Aksara, Jakarta

${ }^{44}$ Diposoedarmo, (2008). Komunikasi Penugasan,. Penerbit PT Toko Gunung Agung, Jakarta

${ }^{5}$ Anoraga, P. dan Widiyanti, N, (2008), Psikologi Dalam Perusahaan, Rineka Cipta, Jakarta.
} 
menghasilkan performance yang rendah. Begitu pula halnya dengan orang yang sebenarnya beability tinggi tetapi rendah motivasinya. ${ }^{6}$

\section{Kesimpulan}

Dari hasil penelitian ini maka dapat disimpulkan bahwa :

1. Komunikasi, disiplin kerja dan motivasi secara bersama-sama berpengaruh signifikan terhadap kinerja.

2. Komunikasi, disiplin kerja dan motivasi masing-masing atau sendirisendiri berpengaruh signifikan terhadap kinerja.

3. Disiplin kerja berpengaruh paling besar terhadap kinerja.

\section{Daftar Pustaka}

Anoraga, P. dan Widiyanti, N, (2008), Psikologi Dalam Perusahaan, Rineka Cipta, Jakarta

As’ad, M. (2007) Psikologi Industri, Penerbit Liberty, Yogyakarta

Arikunto, S. (2003) Prosedur Penelitian Pendekatan Praktek, Bina Aksara, Jakarta.

Baktianto, (2011) Pengaruh Disiplin Dan Motivasi Kerja Terhadap Pegawai Negeri Sipil Kabupaten Grobogan. TESIS. Pasca Sarjana Fak. Ekonomi Universitas Diponegoro, Semarang.

Bambang S, (2011) Kajian Tentang Kepemimpinan Kepala Sekolah Dan Kinerja Guru SMAN 1 Kota Mojokerto. TESIS. Pasca Sarjana Fak. Ekonomi Universitas Gajayana, Malang.

Davis, K dan J. W. Newstorm. (2005). Perilaku Dalam Organisasi. Edisi Bahasa Indonesia. Erlangga, Jakarta

Dessler, G. (2002) Manajemen Sumber Daya Manusia. Edisi Bahasa Indonesia, Prenhallindo. Jakarta

Diposoedarmo, (2008), Komunikasi Penugasan. Penerbit Toko Gunung Agung, Jakarta

${ }^{6}$ As'ad, M. (2007), Psikologi Industri,. Penerbit Liberty, Yogyakarta 
(2009) Manajemen SDM Buku 3. Jakarta:indeks

Faisal, S. (2002) Format-Format Penilaian Sosial : dasar-dasar dan aplikasi. Rajawali Pers. Jakarta

Ghozali, Imam. (2007) Aplikasi Analisis Ultivariate Dengan Program SPSS. Badan Penerbit Universitas Diponegoro. Semarang

Gibson, J.L., J.M. Evansevich, dan J.H. Donnelly (2005) Organisasi, Perlikau, Struktur, Proses.Jilid satu, Edisi Kepadelapan. Alih Bahasa Nunuk Andiarini, Binarupa Aksara. Jakarta Gujurati, D. (2002) Ekonometrika Dasar, Erlangga, Jakarta.

Gomes, F.C. (2005) Manajemen Sumber Daya Manusia, Edisi Bahasa Indonesia, Andi Offset, Yogyakarta.

Handoko, T.H. (2001) Manajemen Personalia Dan Sumberdaya Manusia. Edisi kedua. BPFE. Yogyakarta.

(2008) Manajemen Prsonalia Dan Sumber Daya Manusia. BPFE. Jakarta.

Hasibuan, M.S. P. (2002) Manajemen Sumber Daya Manusia: Dasar Dank Unci Keberhasilan. Gunung Agung. Jakarta.

(2006) Manajemen Sumber Daya Manusia. Penerbit Bumi Aksara. Jakarta

Heidjrachman dan S. Husnan (2003), Manajemen Personalia, BPFE. Jakarta

Indrawijaya, A.I., dan W. Suprapti (2001) kepemimpinan dalam Organisasi: Bahan Ajar Diklatpim Tingkat III. Lembaga Administrasi Negara Republic Indonesia.

Iis Yasiroh (2010) Analisis Pengaruh Insentif, Motivasi, Disiplin Kerja Dan Terhadap Kinerja Pegawai Pada Badan Pengelolaan Keuangan Daerah Kabupaten Mojokerto. TESIS. Pasca Sarjana Fak. Ekonomi Universitas Gajayana Malang.

Judge, T.A., dan J.E. Bono (2007) Five Factors Model Of Personality And FiveFactors Model Of Personality And Transactional Leadership. Journal of applied pshychology, 85 (5) : 751-765

Lili Wahyuni (2009) Pengaruh Komunikasi Terhadap Kinerja Karyawan Bagian Akuntansi Perusahaan BUMN Provinsi Sumatera Utara. TESIS, Program Studi Magister Akuntansi, Universitas Diponegoro, Semarang

Listiono, (2002) Pengaruh Motivasi, Kepuasan Dan Disiplin Kerja Terhadap Kinerja Karyawan (Studi Kasus Di Lingkungan Pegawai Kantor PDAM 
Kota Surakarta). TESIS. Pasca Sarjana Fak. Ekonomi Universitas Sebelas Maret, Solo.

Mangkunegara, A. P. (2009) Manajemen Sumber Daya Manusia Perusahaan. PT Remaja Rosdakarya. Bandung

Muhammad, A. (2009) Komunikasi Organisasi. Ed.1 Cet. 10. Bumi Aksara, Jakarta

Mutiari, S (2006) Pengaruh Organisasi Dan Komunikasi Efektif Terhadap Kinerja Karyawan (Studi Pada PT PLN Area Pelayanan DaNazirn Jaringan Malang). TESIS. Program Pascasarjana Universitas Brawijaya Malang

Mas'ud, F. (2004) Survai Diagnosis Organisasional. Badan Penerbit Universitas Diponegoro. Semarang

Nazir, Moch. (2009), Metode Penelitian, Cetakan Kedua, Ghalia Indonesia, Jakarta

Robbins, S.P. (2007) Perilaku Organisasi; Konsep Kontroversi. Aplikasi Jilid 3. Edisi Bahasa Indonesia. Prenhalindo. Jakarta.

Saydam, G. (2006) Manajemen Sumber Daya Manusia. Edisi Bahasa Indonesia. Gunung Agung Jakarta. 